\title{
Apothecaries Dram Mass Unit
}

National Cancer Institute

\section{Source}

National Cancer Institute. Apothecaries Dram Mass Unit. NCI Thesaurus. Code C64565.

The non-SI unit of mass equal to 60 grains, 3 scruples, $1 / 8$ troy ounce, or approximately 3.8879 grams. 